\title{
Learning Style Preferences of Undergraduate Dietetics, Athletic Training, and Exercise Science Students
}

\author{
Meredith G. Wagner ${ }^{1}$, Pamela Hansen ${ }^{2}$, Yeong Rhee ${ }^{2}$, Ardith Brunt ${ }^{2}$, Donna Terbizan ${ }^{2}, \&$ Bryan Christensen $^{2}$ \\ ${ }^{1}$ Department of Nutrition and Dietetics, Concordia College, Moorhead, MN, USA \\ ${ }^{2}$ Department of Health, Nutrition, and Exercise Sciences, North Dakota State University, Fargo, ND, USA \\ Correspondence: Pamela Hansen, Department of Health, Nutrition, and Exercise Sciences, North Dakota State \\ University, Fargo, ND. USA.
}

Received: February 1, 2014 Accepted: February 16, 2014 Online Published: March 5, 2014

doi:10.11114/jets.v2i2.331

URL: http://dx.doi.org/10.11114/jets.v2i2.331

\begin{abstract}
The study assessed the preferred learning style (LS) of college students and compared LS preferences among students majoring in Dietetics, Exercise Science, and Athletic Training. LS questionnaires were distributed to students ( $N=693$, mean age 20.5 \pm 1.7 ) enrolled in health science courses at three Midwestern universities. Most students preferred a converger LS followed by assimilator, accommodator, and diverger. Some students preferred a combination of two LS. Chi square results indicated a significant relationship between college major and LS. Students in health majors were all observed to have a significant LS preference, namely the converger LS. However, distributions of preferred LS within each major differed. Understanding preferred LS of college students in different academic programs may increase the effectiveness of teaching and learning.
\end{abstract}

Keywords: Learning style, college students, health sciences, converger, assimilator, accommodator, diverger

\section{Introduction}

Undergraduate students are arriving at college with an increased diversity of abilities, skills, and experiences. In turn, these differences are impacting college students' ability to approach and gain new knowledge (otherwise known as their learning style), according to David Kolb's theory of experiential learning (Palermo, Walker, Brown, \& Zogi, 2009). Kolb's theory has been previously detailed by many scholars (Austin, 2004; Heffler, 2001; Jones, Reichard, \& Mokhtari, 2003; Palermo et al., 2009; Pickworth \& Schoeman, 2000; Rassool \& Rawaf, 2007; Wessel et al., 1999) and is based on an individual's assessment of and ability to learn from experience. Kolb proposed that people have different approaches to perceiving, processing, and integrating information, which differ depending upon their circumstances and environment (Austin, 2004).

Kolb's theory is illustrated in a diagram that combines a horizontal and vertical axis to form four quadrants. The horizontal axis represents methods of perception, active or reflective, while the vertical axis represents methods of information processing, concrete or abstract. These axes denote the four learning orientations, which include concrete experience, abstract conceptualization, active experimentation, and reflective observation. According to Smith and Kolb (1996), concrete experimentation reflects an experience-based, involved approach to learning while abstract conceptualization involves a more conceptually-based, analytic approach. An active approach to learning would be defined as active experimentation while an observation-based, impartial approach would be deemed reflective observation.

In addition to the axes representing the learning orientation, the quadrants are formed by these axes. As depicted in Figure 1, the quadrants feature the dominant learning styles. These include converger, which represents a combination of abstract conceptualization and active experimentation; diverger, which represents concrete experience and reflective observation; assimilator, which represents abstract conceptualization and reflective observation; and accommodator, which represents concrete experience and active experimentation (Smith \& Kolb, 1996). 


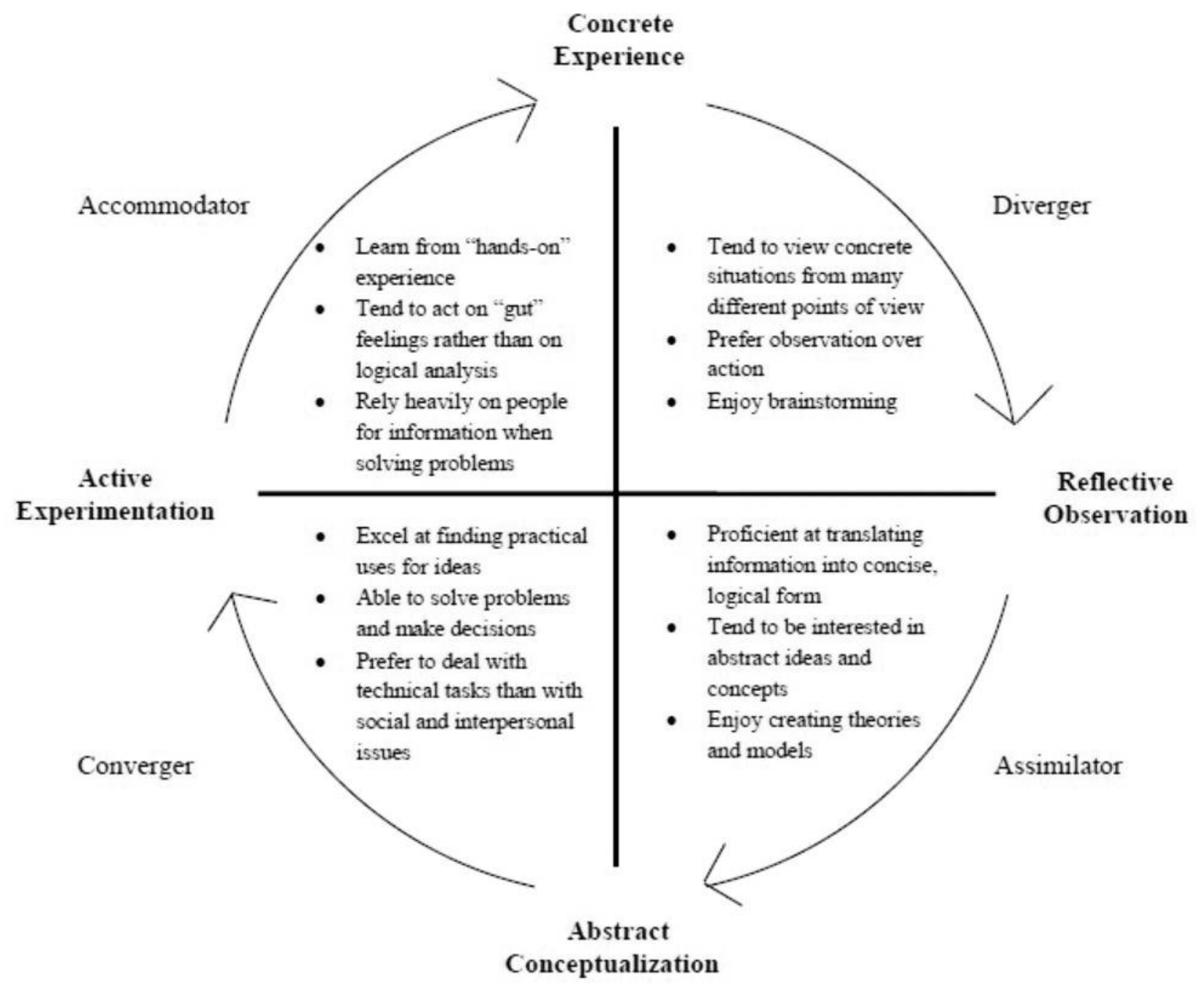

Figure 1. Kolb's model of learning styles. Adapted from Kolb (1985).

According to Smith and Kolb (1996), convergers tend to excel in environments where there is a single answer or solution. These individuals are able to use hypothetical-deductive reasoning to focus on a particular problem and arrive at the single best solution. Convergers are more task-oriented than people-oriented, and can often be found in technological fields where the predominant activity is dealing with objects. Examples of common professions for convergers include computer programmers, farmers, and engineers (Smith \& Kolb, 1996). Alternatively, divergers learn best when allowed to take in information concretely and process it reflectively in order to generate many divergent ideas. They are particularly good at brainstorming. Strengths of divergers include their creativity and ability to understand people. Because they are more feeling-oriented, divergers tend to pursue careers in such fields as psychology, nursing, social work, theater, and journalism (Austin, 2004; Rassool \& Rawaf, 2007; Smith \& Kolb, 1996).

Assimilators tend to focus more on ideas and abstract concepts rather than on people. They possess an ability to take in abstract information and devise an integrated, rational conclusion. Assimilators surpass others in their ability to create models and theories. They prefer to set goals and orchestrate plans systematically, making them ideal candidates to be researchers, librarians, college professors, and writers (Austin, 2004; Smith \& Kolb, 1996). Conversely, accommodators are particularly skillful at adapting to changing environments and circumstances. They are risk takers who enjoy learning through trial and error. Their strengths include leadership and ability to accomplish tasks. For these reasons accommodators tend to seek careers in marketing, government, and business (Rassool \& Rawaf, 2007; Smith \& Kolb, 1996).

With the different learning styles identified by Kolb come different strengths, weaknesses, and capabilities. Recognition of these traits can be beneficial to students in all major areas of study (Heffler, 2001). Given the increase in diversity of experiences within certain professions, including allied health professions, there is an even greater need to understand individual learning styles. Upon entering the workplace, students in allied health professions, which include dietitians, athletic trainers, exercise physiologists, and pharmacists, among others, are experiencing an increasingly complex 
practice environment and are being required to demonstrate increased autonomy (Rassool \& Rawaf, 2007). Gaining knowledge of how they learn most effectively can help students to understand their strengths for dealing with such diverse experiences and may increase their success in their field of study. Thus, pre-professional allied health curricula should help students determine what their preferred learning style is and how it can be strategically used for specific tasks (Hall, 2005).

Previous research among undergraduate students majoring in allied health fields suggests that these students are methodical, attentive, and reliable. Most allied health students have been found to be assimilators (Brower, Stemmans, Ingersoll, \& Langley, 2001; Coker, 2000; Harrelson, Leaver-Dunn, \& Wright, 1998; Leaver-Dunn, Harrelson, \& Wyatt, 1999; Mitchell \& Nyland, 2005; Palermo et al., 2009) or convergers (Coker, 2000; Palermo et al., 2009), preferring hands-on experiences and structured learning environments (Gould \& Caswell, 2006). While commonalities appear to exist among students majoring in allied health fields, it is clear that differences in learning styles exist among students in individual allied health disciplines (Jones et al., 2003). While more recent research on learning styles of students in specific allied health fields has been performed, most has focused on nursing and medical students with minimal research on learning styles of students in other allied health disciplines, including dietetics, athletic training, or exercise science.

The objectives of this study were to assess the preferred learning style of undergraduate college students enrolled in allied health courses and to evaluate if learning style preferences vary among students majoring in dietetics, athletic training, and exercise science. It was hypothesized that learning styles would be related to college major and that college students majoring in dietetics, athletic training, and exercise science would prefer a certain learning style over the others.

\section{Methods}

\subsection{Design}

A cross-sectional research design was used to conduct an exploratory study of the preferred learning styles of college students at three universities in the Midwestern United States. Data were collected and recorded over a four-month period during fall 2009 and fall 2010 semesters. Approval from each university's Institutional Review Board was obtained prior to study implementation.

\subsection{Participants}

A convenience sample of undergraduate college students (mean age $20.6 \pm 1.7$ years) was obtained $(N=590)$ from those currently enrolled in allied health courses at three different institutions in the region. These courses were chosen in order to collect data from freshman to seniors in each major within two years of research, fall 2009 and fall 2010. Participants included full-time students of freshman, sophomore, junior, or senior status. In addition, male and female students of various ethnicities pursuing any of the undergraduate degrees offered through the universities were included.

\subsection{Measures}

The instrument for assessing learning styles of college students was the Learning Style Questionnaire (LSQ). The LSQ was developed by Marshall and Merritt in 1985 and is based on Kolb's Learning Style Inventory (LSI), a tool shown to reliably identify how people learn. Like the LSI, the LSQ has been shown to be a reliable and valid instrument for assessing individual learning style preferences (Marshall \& Merritt, 1986). Specifically, the LSQ has demonstrated content validity and has been recommended for use both in assessment of individual learning styles and for research purposes (Palermo et al., 2009; Pickworth \& Schoeman, 2000). Permission to use the questionnaire was obtained from the authors. Demographic data, including age, gender, major, and year in school, were also collected.

\subsection{Procedures}

The LSQ was administered to all students enrolled and present in selected allied health courses on each campus. Participation was voluntary; no incentives for participation were offered. Written instructions and informed consent were provided and demographic information was collected.

The preferred learning style of students was calculated by adding up the scores of their responses to 40 word pairs included on the LSQ, each of which represented a specific learning dimension. As seen in Figure 2, the four learning dimensions included concrete experience (CE), abstract conceptualization (AC), reflective observation (RO), and active experimentation (AE). Scores for each learning dimension ranged from 0 to 40. In order to determine preferred learning style, the information perceiving (ACCE) score was calculated by subtracting the AC score from the CE score. The information processing (AERO) score was then derived by subtracting the AE score from the RO score. The values of the ACCE and AERO scores then categorized each student's learning style as converger, accommodator, diverger, assimilator, or a combination of two learning styles. 


\begin{tabular}{|c|c|}
\hline Concrete Experience (CE) & $\begin{array}{l}\text { Learning by feeling } \\
\qquad \begin{aligned} \text { - Learning from specific experiences } \\
\text { - Relating to people } \\
\text { - Being sensitive to feelings and people }\end{aligned}\end{array}$ \\
\hline Reflective Observation (RO) & $\begin{array}{l}\text { Learning by watching and listening } \\
\text { - Carefully observing before making judgments } \\
\text { - Viewing issues from different perspectives } \\
\text { - } \quad \text { Looking for the meaning of things }\end{array}$ \\
\hline Abstract Conceptualization (AC) & $\begin{aligned} \text { Learning by thinking } \\
\text { • } \\
\text { - Logically analyzing } \\
\text { - Systematic planning } \\
\text { Acting on an intellectual understanding }\end{aligned}$ \\
\hline Active Experimentation (AE) & $\begin{array}{l}\text { Learning by doing } \\
\qquad \begin{aligned} & \text { - Ability to get things done } \\
&- \text { Risk taking } \\
& \text { - Influencing people and events though action }\end{aligned}\end{array}$ \\
\hline
\end{tabular}

\subsection{Statistical Analyses}

Figure 2. Stages of Learning Cycle. Adapted from Kolb (1985).

The complete data set was statistically analyzed using Predictive Analytic Software (PASW Statistics), version 18.0. An alpha level of $<.05$ was chosen a priori to indicate statistical significance. Chi square test for independence and chi square goodness of fit analyses were performed to determine if there was a significant relationship between learning style and college major and to evaluate if there was a significant preference of learning style among students majoring in dietetics, athletic training, and exercise science.

\section{Results}

\subsection{Descriptive Statistics}

A total of 592 questionnaires were collected and scored; two were removed from analyses due to missing data $(N=590)$. Demographic data are presented in Table 1.

Table 1. Characteristics of Students

\begin{tabular}{llll}
\hline Characteristic & & $n$ & $\%$ \\
\hline Major & & & \\
& Dietetics & 122 & 20.7 \\
& Athletic Training & 56 & 9.5 \\
& Exercise Science & 284 & 48.1 \\
Year in School & Other & 128 & 21.7 \\
& & & \\
& Freshman & 93 & 15.8 \\
& Sophomore & 146 & 24.7 \\
& Junior & 150 & 25.4 \\
& Senior & 135 & 22.9 \\
Gender & $5^{\text {th }}$ Year + & 66 & 11.2 \\
& & & \\
& Male & 215 & 36.4 \\
\hline$N=590$ & Female & 375 & 63.6 \\
\hline & & &
\end{tabular}

Frequencies of preferred learning styles are presented in Table 2. The most common learning style of all the participants was converger $(52.2 \%)$. The next most common was accommodator (19.5\%), followed by assimilator (18.3\%), and 
diverger (3.4\%). Small percentages were found to have a combination of two learning styles (3.1\% accommodator/converger, $2.5 \%$ assimilator/converger, $0.7 \%$ assimilator/diverger, and $0.3 \%$ accommodator/diverger).

Table 2. Preferred Learning Styles

\begin{tabular}{|c|c|c|c|c|c|c|c|c|c|c|}
\hline \multirow[b]{2}{*}{ Learning Style } & \multicolumn{2}{|c|}{$\begin{array}{l}\text { Dietetics } \\
(n=122)\end{array}$} & \multicolumn{2}{|c|}{$\begin{array}{l}\text { Athletic } \\
\text { Training } \\
(n=56)\end{array}$} & \multicolumn{2}{|c|}{$\begin{array}{l}\text { Exercise } \\
\text { Science } \\
(n=284)\end{array}$} & \multicolumn{2}{|c|}{$\begin{array}{l}\text { Other } \\
(n=128)\end{array}$} & \multicolumn{2}{|c|}{$\begin{array}{l}\text { All Majors } \\
(N=590)\end{array}$} \\
\hline & $n$ & $\%$ & $n$ & $\%$ & $n$ & $\%$ & $n$ & $\%$ & $n$ & $\%$ \\
\hline Converger & 71 & 58.2 & 40 & 71.4 & 150 & 52.8 & 47 & 36.7 & 308 & 52.2 \\
\hline Diverger & 4 & 3.3 & 2 & 3.6 & 7 & 2.5 & 7 & 5.5 & 20 & 3.4 \\
\hline Accommodator & 10 & 8.2 & 9 & 16.1 & 52 & 18.3 & 44 & 34.3 & 115 & 19.5 \\
\hline Assimilator & 30 & 24.6 & 3 & 5.3 & 53 & 18.7 & 22 & 17.2 & 108 & 18.3 \\
\hline Accomodator/Diverger & 0 & 0.0 & 0 & 0.0 & 0 & 0.0 & 2 & 1.6 & 2 & 0.3 \\
\hline Accommodator/Converger & 1 & 0.8 & 2 & 3.6 & 13 & 4.6 & 2 & 1.6 & 18 & 3.1 \\
\hline Assimilator/Diverger & 2 & 1.6 & 0 & 0.0 & 1 & 0.3 & 1 & 0.8 & 4 & 0.7 \\
\hline Assimilator/Converger & 4 & 3.3 & 0 & 0.0 & 8 & 2.8 & 3 & 2.3 & 15 & 2.5 \\
\hline
\end{tabular}

\subsection{Model Testing}

Results from the chi square test for independence indicated a significant relationship between college major and learning style, $\chi^{2}(21, N=590)=60.66, p<.05$. The effect size was small $(\Phi=.32$; Cramers $\mathrm{V}=.19)$. Results from the chi square test for goodness of fit indicated dietetics $\left\{\chi^{2}(6, N=122)=226.74, p<.05\right\}$; athletic training $\left\{\chi^{2}(4, N=56)\right.$ $=95.61, p<.05\}$; and exercise science $\left\{\chi^{2}(6, N=284)=413.437, p<.05\right\}$ majors each had a significant learning style preference. The preferred learning style of students in all three majors was the converger learning style.

\section{Discussion}

According to Smith and Kolb (1996), the way individuals learn influences, and is influenced by, their academic training and career choice. The existence of a relationship between college major and learning style suggests that students choose certain disciplines based on their learning style and that their learning style is shaped by their major area of study. Other factors, such as personality type, also play a role in shaping an individual's learning style. The small effect size of the relationship observed in this study suggests that in addition to college major, other factors were related to students' learning style preferences.

In addition to the existence of a relationship between college major and learning style, it was observed that students majoring in dietetics, athletic training, and exercise science all had a preferred learning style. The existence of a preferred learning style among these students, all of whom were majoring in allied health professions, is consistent with previous research indicating that learning styles are sensitive to subject area (Jones et al., 2003). While a preferred learning style emerged among students in each allied health field, the overall distributions of preferred learning styles within each major differed.

\subsection{Dietetic Students}

While there is limited research on preferred learning styles of students majoring in dietetics, the results of this study are similar to those seen in a study of nutrition and dietetics students in Australia (Palermo et al., 2009) but differ from results of dietetics students in Utah. Mitchell and Nyland (2005) found that of the 324 Utah dietetics seniors they surveyed, $29.6 \%$ were assimilators, $27.8 \%$ were accommodators, $21.9 \%$ were divergers, and $20.7 \%$ were convergers. As an occupational group, dietitians have numerous career options, including jobs in clinical dietetics, community or public health, foodservice management, and research and academia (American Dietetic Association, 2011). Careers in clinical dietetics, food service management, and research all require the ability to organize and synthesize information and solve problems using deductive reasoning, all talents of the converger and assimilator (Smith \& Kolb, 1996). Strengths of the accommodator and diverger include leadership, imagination, and creativity (Smith \& Kolb, 1996), and would likely be helpful among dietetics students pursuing careers in community or public health dietetics.

Knowing that the majority of dietetics students surveyed for this study were convergers and assimilators, faculty are able to structure their teaching strategies and plan learning opportunities that will allow for more efficient and effective learning among students (Wessel et al., 1999). In addition to understanding the strengths associated with a particular learning style, there is a need to recognize potential weaknesses so that they may be overcome (Heffler, 2001). While convergers excel in solving problems and making decisions, they are also prone to making hasty decisions or trying to 
solve the wrong problem. Therefore, students with the converger learning style should be challenged to experiment with new ideas and make decisions on the best possible solution. Strengths of assimilators include their ability to plan. However, a tendency to plan may inhibit actual application of knowledge and skills in a practical manner. Learning skills of assimilators can be further developed by including activities that require them to organize information, build conceptual models, design experiments, and collect and analyze quantitative data (Smith \& Kolb, 1996).

\subsection{Athletic Training Students}

In a previous study by Coker (2000), athletic training students in a classroom setting indicated a very different distribution of learning styles than the current study with the majority being assimilators $(65.4 \%)$, followed by convergers $(15.4 \%)$, accommodators $(10 \%)$, and divergers (9.2\%). However, in a clinical setting, the same participants indicated a preference for converger (42.6\%) followed by accommodator (30.8\%) learning styles (Coker, 2000). Other studies of learning style preferences have also observed assimilator to be the preferred learning style of athletic training students (Brower et al., 2001; Leaver-Dunn et al., 1999). These differences serve to emphasize Kolb's assertion that learning styles are not definitive, but rather fluid, and will change with different environments and circumstances (Austin, 2004; Coker, 2000). A shift from a setting focused on theories and abstract thinking, such as a classroom, to a real world situation, which necessitates decision making and problem solving, represents a change in circumstances. This change influences one's ability to grasp information, and thus, impacts his or her preferred learning style (Coker, 2000).

Knowing that the majority of athletic training students in this study preferred the converger learning style can guide faculty towards adopting learning strategies best suited for convergers. Skills of convergers, according to Smith and Kolb (1996), include a highly developed ability to define and solve problems, usually via the use of deductive reasoning. Planning learning experiences that allow students to problem solve, such as exposing them to injured athletes and encouraging them to decide how to best treat the injury, would likely prove beneficial for these students. Strengthening athletic training students' abilities within the other learning styles should also be a focus since too much or too little dependence on any one learning style can present challenges. As Smith and Kolb (1996) explained, insufficient use of divergent skills may prevent students from recognizing the existence of a problem or opportunity while too little reliance on accommodative and assimilative skills can result in students not completing work on time and being unable to learn from mistakes.

\subsection{Exercise Science Students}

This is the only study known to assess, using the LSQ, learning style preferences of undergraduate students majoring in exercise science. The majority of these students were found to be convergers, with assimilation and accommodation preferences also preferred. Since both convergers and assimilators use abstract conceptualization (Smith \& Kolb, 1996), these students learn by analyzing information in a logical manner, systematically planning, and acting on such intellect to guide problem solving. Techniques for further development of learning styles among convergers include encouraging students to experiment with new ideas, set goals, and make decisions while learning for assimilators could be improved by designing experiments to test theories and ideas and then analyzing quantitative data (Smith \& Kolb, 1996). Interestingly, accommodators possess the opposite learning strengths of assimilators. Rather than evaluate information, accommodators prefer to actually perform experiments and be a leader for others (Rassool \& Rawaf, 2007).

The highest prevalence of students with a preference for a combination of two learning styles, otherwise known as dual learning style, was seen among exercise science majors. The accommodator/converger combination was the dual learning style seen in these students. A similarly high prevalence of more than one preferred learning style was seen in a study of 338 undergraduate students studying sports-related programs in the United Kingdom (Peters, Jones, \& Peters, 2008). This dualism, according to Smith and Kolb (1996), signifies that the individual uses one learning style in some situations and the other learning style in other situations. For example, a student may be convergent at tasks while in school and divergent at tasks when at home. Dual learning styles represent the presence of dual strengths but also dual weaknesses. Students who are a combination of accommodator/converger are good at taking action and problem solving but may not see problems or opportunities clearly. Students with a combination of assimilator/converger possess strong analytical and systematic planning skills but tend to spend too much time planning and not enough time implementing the plans. Similarly, students with a combination of assimilator/diverger are skillful in collecting and analyzing information but tend to avoid risks and therefore delay accomplishments (Smith \& Kolb, 1996).

\subsection{Other Students}

Other students surveyed were from different majors offered through the universities, including communication, business, accounting, math, criminal justice, hospitality management, education, apparel and textiles, Spanish and computer science. These students were enrolled in the selected allied health courses at the time of data collection. While students in the "other" category did not indicate dietetics, athletic training, or exercise science as their major, they did 
prefer the converger learning style, which was the same as students majoring in the three allied health disciplines. However, the converger learning style (36.7\%) was only slightly preferred over the accommodator learning style (34.3\%) among students in the "other" category. Research has indicated that successful learning is dependent on learning strategies that are tailored to specific learning styles (Heffler, 2001). Different disciplines tend to fall into specific learning style quadrants (Jones et al., 2003). Pursuing fields in which one's learning style is compatible is believed to be quite common. In fact, changing of a student's major to a discipline that is more suited to his or her learning style has been recommended (Skogsberg \& Clump, 2003). Perhaps students in the "other" category may have enrolled in an allied health course because learning strategies within these courses more appropriately reflected their personal preferred learning style. Research that includes assessment of major and preferred learning styles of college students over time is recommended to determine the influence of preferred learning style on selection of college major.

While this study adds to the body of knowledge regarding learning style preferences among students majoring in specific allied health disciplines, limitations exist that must be noted. One such limitation was that the study consisted of a convenience sample of college students, thereby limiting the generalizability of the results. Another limitation is that length of involvement within a major area of study was not accounted for when determining preferred learning styles of college students. Increased duration of study within a particular program may have impacted students' preferred learning style.

\section{Conclusion}

A major focus among university faculty should be on identifying and incorporating experiences and activities aimed at enhancing learning among students (Pashler, McDaniel, Rohrer, \& Bjork, 2009). Knowledge of an individual's specific learning style has been shown repeatedly to be useful for formulating discussion (Austin, 2004), developing curriculum (Palermo et al., 2009), increasing student control over learning (Jones et al., 2003), and promoting self-reflection (Austin, 2004). These benefits represent numerous possibilities for improving academic performance among college students in all majors (Jones et al., 2003). It has been shown that individuals with different learning styles tend to approach learning in distinctive ways, yet many students are not consciously aware of their learning style preference (Jones et al., 2003). It is, therefore, necessary to help students identify their preferred learning style and incorporate knowledge of those preferences to promote heightened understanding and improved learning (Hall, 2005; Heffler, 2001). In this study, the majority of dietetics, athletic training, and exercise science students preferred the converger learning style while the distributions of other learning styles within each major varied considerably. Such identification of preferred learning styles, as demonstrated in this study, is relatively quick, yet provides valuable information about college students that can be used to enhance learning and later performance as professionals in the field. Future research should focus on assessing the preferred learning styles of college students from all allied health majors and include follow-up assessments of students' learning style preferences and major area of study throughout their academic tenure.

\section{References}

American Dietetic Association. (2011). Careers in dietetics. Retrieved from http://www.eatright.org/WorkArea/linkit.aspx?LinkIdentifier=id\&ItemID=6442459107\&libID=6442459103

Austin, Z. (2004). Learning styles of pharmacists: Impacts on career decisions, practice patterns and teaching method preferences. Pharmacy Education, 4(1), 13-22. http://dx.doi.org/10.1080/1560221042000193310

Brower, K. A., Stemmans, C. L., Ingersoll, C. D., \& Langley, D. J. (2001). An investigation of undergraduate athletic training students' learning styles and program admission success. Journal of Athletic Training, 36(2), 130-135.

Coker, C. A. (2000). Consistency of learning styles of undergraduate athletic training students in the traditional classroom versus the clinical setting. Journal of Athletic Training, 35(4), 441-444.

Gould, T. E., \& Caswell, S. V. (2006). Stylistic learning differences between undergraduate athletic training students and educators: Gregorc Mind Styles. Journal of Athletic Training, 41(1), 109-116.

Hall, E. (2005). Learning styles - is there an evidence base for this popular idea? Education Review, 19(1), 49-56.

Harrelson, G. L., Leaver-Dunn, D., \& Wright, K. E. (1998). An assessment of learning styles among undergraduate athletic training students. Journal of Athletic Training, 33(1), 50-53.

Heffler, B. O. (2001). Individual learning styles and the learning style inventory. Educational Studies, 27(3), 307-316. http://dx.doi.org/10.1080/03055690120076583

Jones, C., Reichard, C., \& Mokhtari, K. (2003). Are students' learning styles discipline specific? Community College Journal of Research and Practice, 27, 363-375. http://dx.doi.org/10.1080/10668920390128988

Kolb, D. A. (1985). Learning Style Inventory technical manual. Boston, MA: McBer \& Company. 
Leaver-Dunn D., Harrelson, G. L., \& Wyatt, T. (1999, January). Critical thinking disposition and learning styles among students in two CAAHEP-accredited undergraduate athletic training education programs. Paper presented at the Athletic Training Educator's Conference in Fort Worth, TX.

Marshall, J. C., \& Merritt, S. L. (1986). Reliability and construct validity of the Learning Style Questionnaire. Educational and Psychological Measurement, 46, 257-262. http://dx.doi.org/10.1177/0013164486461031

Mitchell, A. W., \& Nyland, N. K. (2005). Learning styles differ between senior dietetics students and dietetic faculty members. Journal of the American Dietetic Association, 105, 1605-1608. http://dx.doi.org/10.1016/j.jada.2005.07.008

Palermo, C., Walker, K. Z., Brown, T., \& Zogi, M. (2009). How dietetics students like to learn: Implications for curriculum planners. Nutrition \& Dietetics, 66, 108-112. http://dx.doi.org/10.1111/j.1747-0080.2009.01337.x

Pashler, H., McDaniel, M., Rohrer, D., \& Bjork, R. (2009). Learning styles: Concepts and evidence. Psychological Science in the Public Interest, 9(3), 105-119.

Peters, D., Jones, G., \& Peters, J. (2008). Preferred 'learning styles' in students studying sports-related programmes in higher education in the United Kingdom. Studies in Higher Education, 33(3), 155-166. http://dx.doi.org/10.1080/03075070801916005

Pickworth, G. E., \& Schoeman, W. J. (2000). The psychometric properties of the Learning Style Inventory and the Learning Style Questionnaire: Two normative measures of learning styles. South African Journal of Psychology, 30(2), 44-52.

Rassool, G. H., \& Rawaf, S. (2007). Learning style preferences of undergraduate nursing students. Nursing Standard, $21(32), 35-41$.

Skogsberg, K., \& Clump, M. (2003). Do psychology and biology majors differ in their study processes and learning styles? College Student Journal, 31(1), 27-33.

Smith, D. M., \& Kolb, D. A. (1996). User's guide for the Learning-Style Inventory: A manual for teachers and trainers. Boston, MA: McBer \& Company.

Wessel, J., Loomis, J., Rennie, S., Brook, P., Hoddinott, J., \& Aherne, M. (1999). Learning styles and perceived problem-solving ability of students in a baccalaureate physiotherapy programme. Physiotherapy Theory and Practice, 15, 17-24.

\section{$(\mathrm{cc}) \mathrm{BY}$}

This work is licensed under a Creative Commons Attribution 3.0 License. 